Thorax, 1980, 35, 164-170

\title{
Multiple exercise and histamine challenge in asthmatic patients
}

\author{
ROBIN E SCHOEFFEL, SANDRA D ANDERSON, I GILLAM, AND D A LINDSAY
}

From the Department of Thoracic Medicine, Royal Prince Alfred Hospital, Camperdown, NSW, and the Department of Thoracic Medicine, Royal Children's Hospital, Parkville, Victoria, Australia

ABSTRACT We studied the effects of repeated exercise and histamine challenge in asthmatic patients to determine the frequency and degree to which a state of refractoriness was induced by these stimuli. Twenty-nine patients performed three exercise tests, and on a separate day 16 of these $\mathrm{P}^{\infty}$ patients had three histamine inhalational challenge tests. Forty minutes separated each challenge 5 Changes in airways resistance were measured using the peak expiratory flow rate (PEFR). The fall in PEFR (expressed as a percentage of the pre-challenge value) was used to quantify the response tow challenge. Significant "protection" was defined as a fall in PEFR after a repeated challenge less tharß $50 \%$ of the fall observed on the first challenge. All patients had a fall in PEFR greater than $22 \%$ on the first challenge of the day. With repeated exercise 28 out of 29 patients had a fall in PEFRO less than that observed on the first test and 12 had significant "protection". The fall in PEFR after the third exercise challenge was not significantly different to the second challenge and a "plateau' effect was observed. There was no significant difference in the fall in PEFR after the first and seconof histamine challenge although two of the 16 patients were significantly protected. After the thirfs histamine challenge five of the 16 patients were significantly protected from the effects of the same dose of histamine. The degree to which repeated exercise challenge induces a diminished response is variable. With repeated challenge the response to histamine remains relatively constant in mos $B$ patients though $30 \%$ may be expected to be refractory after a third challenge.

In 1966, McNeill and associates ${ }^{1}$ suggested that repeated exercise challenge at intervals of 45 minutes progressively diminished the postexercise increase in airways resistance in patients with asthma. James et $a l^{2}$ confirmed this in a study of 10 asthmatics who performed multiple walking tests at intervals of one hour. Edmunds et $a l^{3}$ reported a refractory period after exerciseinduced asthma in eight asthmatic patients who performed running exercise tests 30 minutes apart.

The reason for this diminished bronchoconstrictor response after repeated exercise is unclear. These authors suggested that a depletion in stores of mediators potentially capable of inducing bronchoconstriction occurred after the initial exercise stimulus, and that a time interval may have been required to replenish them.

The airways of patients with asthma are exquisitely sensitive to histamine, ${ }^{4}$ and it is possible that this may be one of the mediators of bronchoconstriction depleted with repeated exer-

Address for reprint requests: Dr SD Anderson, Department of Thoracic Medicine, Royal Prince Alfred Hospital, Camperdown, 2050 NSW, Australia. cise challenge. Alternatively, it is possible tha the bronchial smooth muscle may become refractory to repeated stimulation by these mediators. This hypothesis would be difficult to prove in vivo.

We investigated the effects of repeated exercise and histamine challenge in asthmatic patients tof determine the frequency and degree to which state of refractoriness was induced by these stimuli.

\section{Patients and methods}

Twenty-nine patients (19 males, 10 females? aged 9-33 years with a mean of 15 years) were studied. All had asthma as defined by Scadding, and used aerosol beta-sympathomimetics regu? larly. Some required sodium cromoglycate andए beclomethasone dipropionate for control of theip symptoms. All medications were discontinue for at least six hours before testing and nonę was administered on the test days before compleg tion of the exercise and histamine challenges Exercise-induced asthma (EIA), defined as a falP 
in peak expiratory flow rate (PEFR) after exercise greater than $10 \%$ of the pre-exercise level, ${ }^{6}$ had been demonstrated in all patients during a routine laboratory assessment.

The patients were selected for the study because they recovered sufficiently from an attack of EIA within half an hour and were able to perform repeated exercise challenge. The intensity and duration of exercise was selected for each patient on the basis of an initial laboratory test.

Each patient ran for six or eight minutes on a treadmill (Avionics, California, USA). The speed (range 5.5-8.5 Kph) and the slope (range $5-13 \%$ ) of the treadmill remained constant for each patient for all tests.

Peak expiratory flow rates were measured with a calibrated Wright Peak Flow Meter (Airmed Ltd, UK); the best of three attempts was recorded. Flow rates were measured at rest, and at $1,3,5,7,10$, and 15 minutes post-exercise, at which time the patient ran for a further minute to facilitate recovery from EIA. Another exercise test was performed 16-18 minutes later. Thus an interval of 40 minutes elapsed between runs.

On a separate day 16 of the patients (12 men and four women) returned to the laboratory and three bronchial challenges using histamine acid phosphate (David Bull Laboratories, Victoria, Australia) were performed.

Since the measurement of forced expiratory volume in one second $\left(\mathrm{FEV}_{1}\right)$ is more commonly reforted for the response to inhaled histamine a Minato Medical Science Autospirometer (Osaka, Japan) which records PEFR and $\mathrm{FEV}_{1}$ simultaneously was used. The autospirometer was calibrated for flow using a rotameter (GEC Elliot, Croydon, UK) and a Hoover vacuum which generated variable flow rates and for volume using a calibrated volume syringe.

Before the first challenge, prick skin tests were performed using the standardised dilutions of histamine acid phosphate (histamine) recommended for inhalational challenge ${ }^{7}(0.03,0.06$, $0 \cdot 12,0.25,0.5,1 \cdot 0,2 \cdot 5,5.0 \mathrm{mg} / \mathrm{ml})$. The buffered diluent (pH 7.383 \pm 0.005 ) was used as the control. The initial concentration of histamine used for the bronchial challenge was one dilution below that which elicited a $2 \times 2 \mathrm{~mm}$ weal 10 minutes after the prick skin test.

Solutions were inhaled from a No 40 De Vilbiss nebuliser which was attached to a cylinder of compressed medical air set to deliver eight litres per minute. A nose clip was used to clamp the patient's nostrils.
The patient inhaled five inspiratory capacities of the control solution. One minute later two measurements of PEFR and $\mathrm{FEV}_{1}$ were made. The best value was recorded. The protocol was then repeated using histamine, the concentration of which was increased until a fall in PEFR, similar to that which was induced by the first exercise test, was observed. After this concentration of histamine PEFR and FEV 1 were measured at $3,5,7,10$, and 15 minutes.

For subsequent challenges the concentration of histamine administered was equal to the sum of the concentrations of the solutions used for the first challenge so that the number of breath units remained the same for all three tests. ${ }^{7}$ An interval of 40 minutes separated each challenge. At the end of each test day patients were given an aerosol beta-sympathomimetic to ensure complete recovery from airways obstruction.

The protocol was approved by the Ethics Committee of the Royal Prince Alfred Hospital and was carried out after informed consent was given by the patients.

The decrease in PEFR and $\mathrm{FEV}_{1}$ in response to exercise and histamine challenge was quantified as follows:

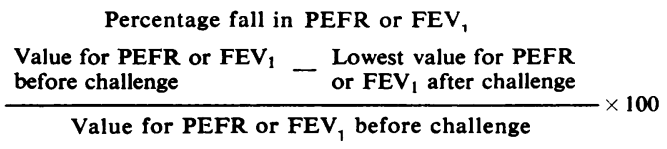

To assess the effect of repeated challenge in each patient an "index of protection", defined as the difference in the percentage fall in PEFR between the two tests expressed as a percentage of the fall of the first, was used.

A value of $50 \%$ or more was regarded as "significant protection", since the coefficient of variation for the percentage fall in PEFR after repeated running tests performed within a period of one week is $20-25 \% .{ }^{8-10}$ The same value and index was used by Godfrey and Konig ${ }^{11}$ to assess the protective effect of a drug in EIA.

Predicted values for PEFR were taken from the data of Godfrey et al ${ }^{12}$ for children and from that of Cotes $^{13}$ for adults. The data were analysed using a $t$ test for paired values in the same subject A two-way analysis of variance was used to determine whether there was a difference between the means of the three tests. The multiple range test of Duncan ${ }^{14}$ was used to determine the level of significance. The coefficient of variation for the percentage fall in PEFR for repeated histamine challenge was determined to assess its reproducibility. It was derived from the standard deviation of the difference between the percen- 
tage fall after the first and second histamine challenges, and expressed as a percentage of the overall mean.

\section{Results}

\section{EXERCISE}

Individual values for the percentage fall in PEFR for the first and second exercise test are illustrated in fig 1. After the first test there was a fall in PEFR greater than $22 \%$ of the preexercise value in all patients. There was no correlation $(r=0.09, p$ NS) between the pencentage fall in PEFR after exercise and the pre-exercise value for PEFR expressed as a percentage of predicted normal.

Complete recovery from EIA did not occur in all patients and values for PEFR before the second run were lower (table 1). The percentage fall in PEFR was less after the second exercise test in all but one of the patients and for the group this reduction was significant (table 1). However, EIA still occurred in 26 of the 29 patients and only 12 patients were afforded significant protection (table 2).

Resting levels of PEFR before the third exercise test were similar to those observed before the second test, but still lower than those observed before the first. There was no significant difference in the percentage fall in PEFR after the third test compared with the second

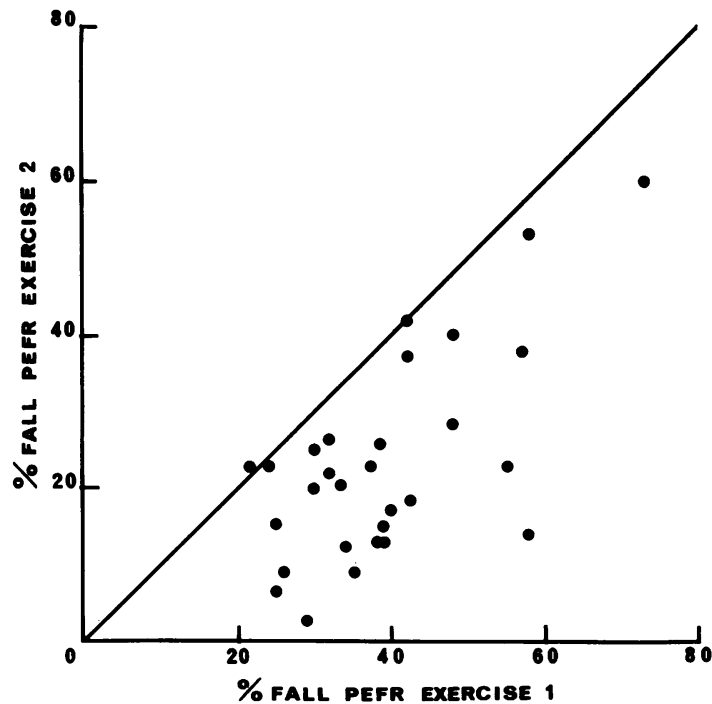

Fig 1 Individual values for percentage fall in peak expiratory flow rate (PEFR) after the first and second exercise challenge. $-=$ the line of identity.
Table 1 Values for peak expiratory flow rate (PEFR) expressed as a percentage of predicted normal before each challenge and values for percentage fall in PEFR after each challenge

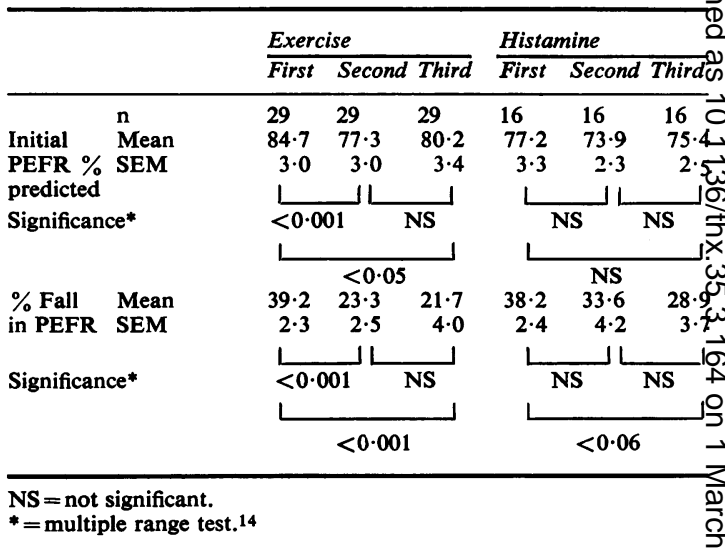

test and a "plateau" effect was demonstratedö (table 1).

Twenty-four of the patients still had a fall in PEFR greater than $10 \%$ after the third exercise test and again only 12 patients had significant protection compared with their initial responsen (table 2).

\section{HISTAMINE}

Individual values for percentage fall in $\operatorname{PEFR}^{3}$ after the first and second histamine challenge are plotted in fig 2. The percentage fall in PEFR after the first challenge was significantly cor related with the percentage fall in PEFR aftero the second challenge $(r=0.61, p<0.01)$. There was no significant change in the response to the two tests for the group (table 1) but two patients had significantly less response to histamine after the second challenge (table 2).

The response to repeated histamine challenge was very reproducible and the within-patient coefficient of variation for the percentage fall in

Table 2 Number of patients with different degrees $N$ of protection after repeated challenges-29 patients $\mathrm{N}$ with exercise $(E), 16$ patients with histamine $(H)$

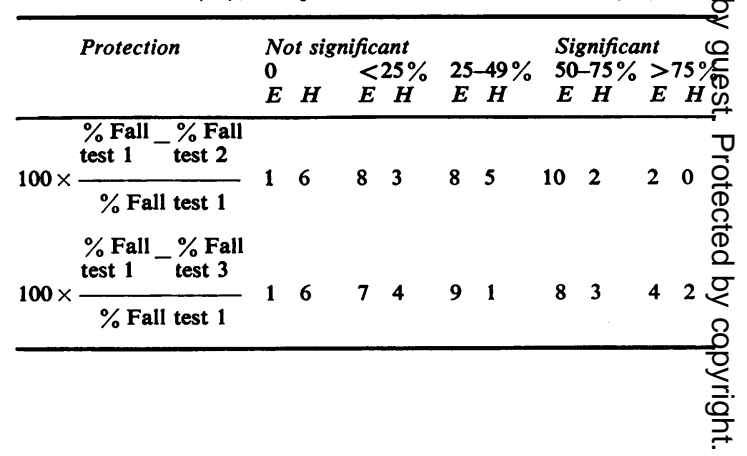




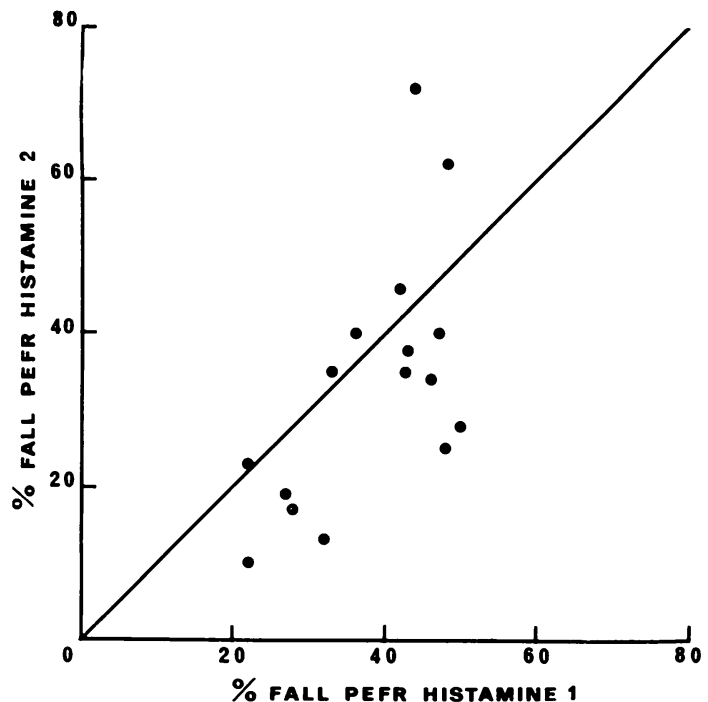

Fig 2 Individual values for percentage fall in PEFR after the first and second histamine challenge. $-=$ the line of identity.

PEFR between the two challenge tests was only $27 \%$.

There was a significant correlation $(r=0.81$, $\mathrm{p}<0.001)$ between the percentage fall in PEFR and $\mathrm{FEV}_{1}$ after the histamine challenges (fig 3). The percentage fall in PEFR was similar after the second and the third challenges. However, when the percentage fall in PEFR after the third challenge was compared with the percentage fall after the first challenge it was significantly reduced (table 1).

Patients recovered rapidly from the effects of

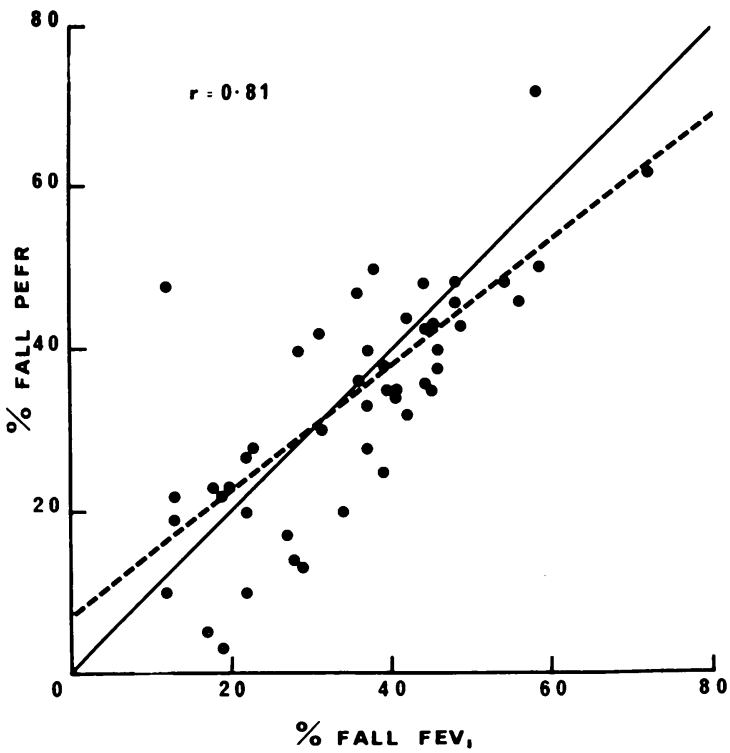

Fig 3 Relationship between percentage fall in $P E F R$ and in forced expiratory volume in one second observed after histamine challenge. Individual values are given for the 16 patients who received three challenges. $-=$ the line of identity, $\cdots--=$ the regression line, $r=$ the correlation coefficient.

histamine challenge and values for PEFR were not significantly different before each challenge (table 1).

\section{EXERCISE AND HISTAMINE}

Sixteen patients completed both test days. They have been divided into two subgroups on the basis of their response to the second exercise test.

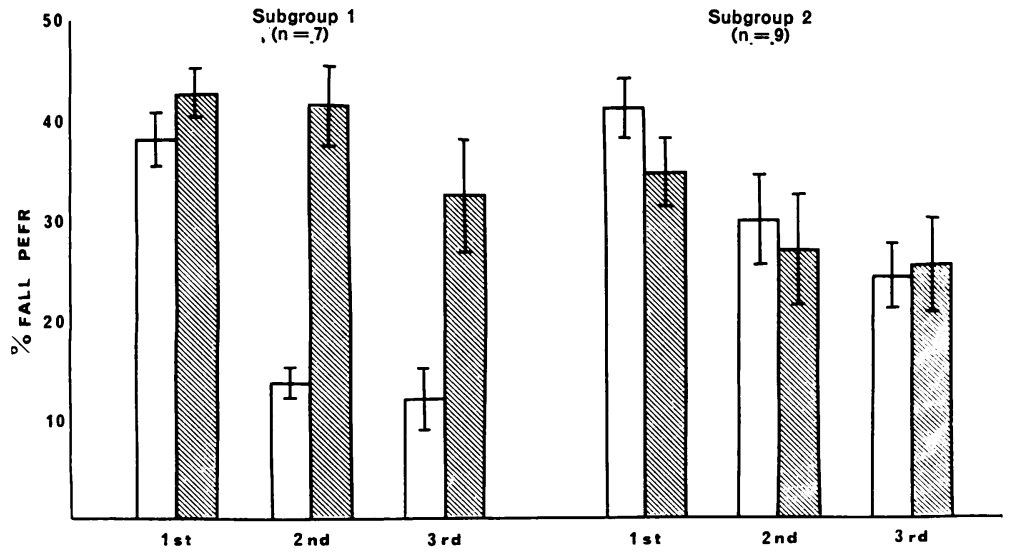

Fig 4 Mean values \pm 1 standard error of the mean for the percentage fall in PEFR after each exercise and each histamine challenge for the 16 patients who completed all tests. For definition of subgroups see text. 
The mean values \pm SEM for percentage fall in PEFR after each challenge are given for the subgroups in fig 4. The pre-challenge values for PEFR for each subgroup were not significantly different.

Subgroup 1 comprised the seven patients who had a $50 \%$ or greater protection from their EIA and thus were relatively refractory to the effects of repeated exercise. After the second exercise test the percentage fall in PEFR was significantly reduced $(\mathrm{p}<0.001)$. There was no difference in the percentage fall in PEFR after the second and third tests. Repeated challenge with histamine did not induce a "state of refractoriness" in these patients. The percentage fall in PEFR after all three histamine challenges was not significantly different.

Subgroup 2 comprised the remaining nine patients in whom less than $50 \%$ protection was observed after the second run. In these patients the percentage fall in PEFR after the second test was significantly less than the fall after the initial test $(\mathrm{p}<0.005)$ but the response to histamine after the first and second challenge was not significantly different.

\section{Discussion}

In studying the frequency and degree to which a state of refractoriness is induced by repeated challenge with exercise and histamine, we have been able to demonstrate that in patients who are refractory to a second or third exercise test there is no significant change in the response to exogenously administered histamine. Thus, for these patients the diminished bronchoconstrictor response after exercise could not be accounted for by failure of the bronchial smooth muscle to respond to repeated stimulation by histamine, thereby providing further evidence that depletion of mediator stores is the mechanism for refractoriness in EIA.

Results of the present study showed that there is considerable variation in the degree to which repeated exercise challenge induces a diminished bronchoconstrictor response in patients with moderate to severe EIA. Significant protection from EIA was afforded in one-third of the patients after a second or third test, but in only four patients was EIA completely abolished after the third challenge. The reasons for this variability in response are unclear. However, the time interval between tests appears to be an important factor.

Edmunds et $a l^{3}$ observed significant protection from EIA in seven of their eight patients when the interval between tests was 30 minutes. After the second test the decrease in PEFR in theiro patients was only $31 \%$ of that observed after흠 the first test. In our study 12 of the 29 hads significant protection from EIA on repeated $\mathbb{Q}$ challenge 40 minutes apart. For the group the decrease in PEFR was $59 \%$ of that observedon the first run. In the study of James et al only two of the 10 patients were protected from EIA when 60 minutes separated the two tests.? The second walking test induced a decrease in $\vec{x}$ PEFR which was $82 \%$ of that which was ob served on the first test. Thus it appeared that stepwise increments of the time interval betweenexercise tests from 30 to 40 and 60 minutes permitted an increasing number of patients tof recover from their refractory state. This timedependent relationship between EIA and repeated exercise, reflected in diminishing protection with longer intervals, is consistent? with the hypothesis that mediators of broncho $\overrightarrow{0}$ constriction are depleted after the first episode 0 of EIA and must be replenished before a second episode of equal severity can occur.

Many mediators could be responsible for EIA -for example, histamine, slow-reacting sub stance of anaphylaxis, thromboxane $A_{2}$, and $\frac{D}{2}$ prostaglandin $F_{2} \propto$. We chose histamine since it is known to be released from the lung in response to mechanical stimulation and exercise, ${ }^{15-17}$ it is a pre-formed mediator in masto cells reported to be in the bronchial mucosa. and sub-mucosa, ${ }^{18-19}$ it may become depleted and is rapidly metabolised, ${ }^{20}$ asthmatic patients recover quickly from the bronchoconstriction induced by it, ${ }^{21}$ and the response to repeated 3 . challenges performed within one week has beeris reported to be highly reproducible. ${ }^{22}$

The mechanism by which histamine induces bronchial smooth muscle contraction is not clear. It is thought to act both reflexly througla cholinergic pathways ${ }^{23}$ and directly on the smooth muscle. ${ }^{24} 25$ It would appear to be in dependent of mediator release since no pro $N$ tection is afforded by disodium cromoglycate. ${ }^{20 \mathrm{~W}}$ Recent studies have demonstrated that the $\mathrm{H}_{\mathrm{O}}^{\mathrm{\omega}}$ receptor antagonists clemastine and chlorphen iramine competitively antagonise histamine $\frac{-}{D}$ induced bronchospasm ${ }^{24}{ }^{25}$ while ipratropium? bromide, an anticholinergic agent has no effect. ${ }^{24}$ This suggests that the primary effect of histamine is through the $H_{1}$ receptors on the smooth muscle.

Since an increase in arterial plasma histamine has been demonstrated in some patients with EIA, ${ }^{17} 27$ it is possible that bronchoconstriction 
occurs as a result of stimulation of the $\mathrm{H}_{1}$ receptors. However, other mediators of bronchoconstriction may be released simultaneously with histamine.

It should be noted that the patients performed exercise tests and histamine challenge on separate days. Additional information concerning preservation of bronchial reactivity to histamine in patients refractory to repeated exercise may be obtained by substituting a histamine challenge for the third exercise test. A more complete picture of bronchial reactivity may result from studies in which other putative mediators of bronchoconstriction, such as slowreacting substance and thromboxane $\mathrm{A}_{2},{ }^{28}$ are used in bronchial challenge. The present conclusions are contingent upon the possibly incorrect assumption that the response of bronchial smooth muscle to these other mediators is mimicked by histamine.

A further explanation invoking multiple causal factors in EIA-including mediator release and intrinsic bronchial hyperreactivitymay also account for the present findings as follows: the smaller fall in PEFR after the second exercise test is the result of depletion of mediators and the residual bronchoconstriction (of similar magnitude after the second and third exercise tests) reflects bronchial hyperreactivity independent of mediator release. Moreover, if mediator depletion were solely responsible for the refractory state, one might expect a correlation between the severity of an initial episode of EIA and the degree of protection during a second exercise test. Such a correlation does not exist $(\mathrm{r}=0.08 ; \mathrm{p}>0.1)$, providing additional evidence to implicate multiple causal factors in EIA.

Extrinsic factors were unlikely to be responsible for the diminished response to exercise since the intensity of work was constant and the environmental conditions (temperature and relative humidity) were similar for the three tests performed by each patient.

Exercise alone does not induce a state of smooth muscle refractoriness. In a previous study using the same time interval between runs we have demonstrated that a marked fall in flow rates can occur after a second test when EIA is blocked by the inhalation of hot humid air on the initial run. ${ }^{29}$

A proportion of our patients had a diminished response to repeated challenge with the same dose of histamine. After the third histamine challenge five patients had falls in PEFR less than $50 \%$ of the fall observed on the initial test of the day, and three of these patients had a fall in PEFR after the third challenge of $10 \%$ or less. It is not known whether higher concentrations of histamine would have provoked a further response in these patients. A change in sensitivity of the bronchial smooth muscle $\mathrm{H}_{1}$ receptor, or a difference in the distribution of the aerosol with subsequent challenges may account for the diminished response in some patients. While there was no significant difference in the pre-challenge values for PEFR for any test there may have been changes in the calibre of the small airways not reflected by the measurement of PEFR.

In conclusion, the degree to which a state of refractoriness is induced by repeated exercise challenge is variable. By contrast the bronchoconstrictor response to repeated challenge with histamine remains relatively constant in most patients, though $30 \%$ of patients may be expected to be relatively refractory to the same dose of histamine after a third challenge. Indirect evidence favours depletion of pharmacological mediators rather than refractoriness of bronchial smooth muscle as one of the possible mechanisms in EIA.

This work was supported in part (RES) by a grant from the Asthma Foundation of New South Wales. We would like to thank Dr JP Seale and the Thoracic Physicians of the Page Chest Pavilion.

\section{References}

1 McNeill RS, Nairn JR, Millar JS, Ingram CG. Exercise-induced asthma. $Q J$ Med 1966; 35: 55-67.

2 James L, Faciane J, Sly RM. Effect of treadmill exercise on asthmatic children. $J$ Allergy Clin Immunol 1976; 57:408-16.

3 Edmunds AT, Tooley M, Godfrey S. The refractory period after exercise-induced asthma: its duration and relation to the severity of exercise. Am Rev Respir Dis 1978; 177:247-54.

4 Curry JJ. Comparative action of acetyl-betamethylcholine and histamine on the respiratory tract in normals, patients with hay fever and subjects with bronchial asthma. J Clin Invest 1947; 26:430-8.

5 Scadding JG. Patterns of respiratory insufficiency. Lancet 1966; 1:701-5.

6 Anderson SD, Rozea PJ, Dolton R, Lindsay DA. Inhaled and oral bronchodilator therapy in exercise-induced asthma. Aust NZ J Med 1975; 5:544-50.

7 Chai H, Farr RS, Froehlich LA et al. Standardisation of bronchial inhalation challenge 
procedures. J Allergy Clin Immunol 1975; 56: 323-7.

8 Silverman M, Anderson SD. Standardization of exercise tests in asthmatic children. Arch Dis Child 1972; 47:882-9.

9 Eggleston PA, Beasley P, Guerrant JG. Standardization of exercise-induced asthma. $J$ Allergy Clin Immunol 1976; 57:251.

10 Chan-Yeung M. The effect of SCH 1000 and disodium cromoglycate on exercise-induced asthma. Chest 1977; 71:320-3.

11 Godfrey S, König P. Inhibition of exerciseinduced asthma by different pharmacological pathways. Thorax 1976; 31:137-43.

12 Godfrey S, Kamburoff PL, Nairn JR. Spirometry, lung volumes and airway resistance in normal children aged 5-18 years. $\mathrm{Br} J$ Dis Chest 1970 ; 64:15-24.

13 Cotes JE. Lung function. Oxford: Blackwell Scientific Publications, 1968: 381.

14 Duncan DB. Multiple range and multiple Ftests. Biometrics 1955; 11:1-42.

15 Piper $P$, Vane J. The release of prostaglandins from lung and other tissues. Ann NY Acad Sci 1971; 180:363-85.

16 Dunér H, Pernow B. Histamine and leucocytes in blood during muscular work in man. Scand $J$ Clin Lab Invest 1958; 10:394-6.

17 Ferris L, Anderson SD, Temple DM. Histamine release in exercise-induced asthma. $\mathrm{Br}$ Med J 1978; 1:1697.

18 Brinkman GL. The mast cell in normal bronchus and lung. J Ultrastruct Res 1968; 23: 115-23.

19 Patterson R, McKenna JM, Suszko IM et al. Living histamine-containing cells from the bronchial lumens of humans. J Clin Invest 1977; 59:217-25.

20 Beal GN, Vanarsdel PP Jr. Histamine meta- bolism in human disease. J Clin Invest 1960: 39:676-83.

21 Itkin IH. Bronchial hypersensitivity to mecholy and histamine in asthma subjects. $J$ Allergy 1967; 40:245-56.

22 Juniper EF, Frith PA, Dunnett C, Cockcrof to DW, Hargreave FE. Reproducibility and com-s parison of responses to inhaled histamine and $\overrightarrow{0}$ methacholine. Thorax 1978; 33:705-10.

23 Sellick H, Widdicombe JG. Stimulation of lung $\vec{\omega}$ irritant receptors by cigarette smoke, carbon? dust, and histamine aerosol. J Appl Physiol 1971; 31:15-19.

24 Woenne R, Kattan M, Orange RP, Levison of Bronchial hyperreactivity to histamine and methacholine in asthmatic children after inhala- $\AA$ tion of SCH 1000 and Chlorpheniramine maleate.음 J Allergy Clin Immunol 1978; 62:119-24.

25 Nogrady SG, Bevan C. Inhaled antihistamines -broncho-dilation and effects on histamine and methacholine-induced bronchoconstriction. $\frac{\text { S }}{5}$ Thorax 1978; 33:700-4.

26 Kang B, Townley RG, Lee CK, Kolotkin BM. Bronchial reactivity to histamine before and. after sodium cromoglycate in bronchial asthma. Br Med J 1976; 1:867-70.

27 Simon RA, Ginsberg M, Timms RM, Stevenson DD. Exercise induced bronchospasm: a study of plasma mediators. Proceedings of the 35 th $\frac{\bar{Q}}{2}$ meeting of the American Academy of Allergy, New Orleans, Louisiana, 1979.

28 Hedquist P, Mathé AA. Role of prostaglandins in asthma. In: Lichtenstein LM, Austen KF (eds). Asthma, physiology, immunopharmacology, vol 2. London: Academic Press, 1977.

29 Anderson SD, Daviskas E, Schoeffel RE, Unger SF. Prevention of severe exercise-induced asthma $\underset{x}{\stackrel{0}{*}}$ with hot humid air. Lancet 1979; 2:629. 